\title{
Recent Development in Hybrid Electrical Vehicle
}

\author{
Amith A. Kulkarni, Dhanush P., Chethan B.S., Thamme Gowda C.S. and Prashant Kumar Shrivastava* \\ Department of Mechanical Engineering, Vidyavardhaka College of Engineering, Mysuru, Karnataka, India; \\ Amith.kulkarni.54@gmail.com, Dhanushp147@gmail.com, Chethanbs050@gmail.com, \\ Thammegowda.CS@vvce.co.in, er.prashant1986@gmail.com
}

\begin{abstract}
Objective: Automotive is one of the most leading sectors in the fuel consumption and also responsible for the air pollution, hence it has become a necessity to switch from the conventional machine to the electric vehicles as to reduce the environmental hazard impacts, and based on the recent technologies the various electric vehicles have been introduced. Methods/statistical analysis: The electric vehicles have various advantages over the conventional cars as they maintain the emission and greenhouse gases, as they have a higher energy conversion efficiency, but the only disadvantages of the electric vehicles are the consistent replacement of the batteries, but that can also be replaced by recharging the battery through the renewable source of energy and the techno-economic model design of the vehicle will lead to evaluation of the unitary operating cost per electric drive vehicles using a methodology based on the depreciation charges and maintenance expenses. Findings: The finding of this work is to explore new and advanced hybrid technology that will help to improve the automobile industries and reduce the dependency on fossil fuel that also reduces the air pollution by the hybrid electric vehicles. Application/improvement: In this study, we have discussed the hybrid electric vehicle and its applications in various fields like electric bikes, electric cars, electric buses and other transportation and commercial purpose also. Now the Indian government also focuses on this sector and providing the subsidy for the buyers and manufacturers of electric vehicles.
\end{abstract}

Keywords: Hybrid Electric Vehicle, Air Pollution, Power Battery, Artificial Intelligence, Modelling

\section{Introduction}

Now a day's pollution is the biggest problem in INDIA or worldwide. There are different types of pollutions such as air, water, soil, thermal pollution, noise pollution, light pollution, and radioactive pollution. All kinds of pollutions are direct effects on human beings and the atmosphere. Air pollution is a highly effected type of pollution that affects human life in very little time and also responsible for breathing issues, asthma, cancer, and many dangerous diseases. The hybrid electric vehicles are the new alternative solution to reduce the dependency of the fossil fuel and also to reduce the pollution dependency, the factor to be considered for hybrid electric vehicles (HEVs) is the fuel economy. And this factor is dependent on the driving patterns of the HEVs, the driving patterns are variable, as it can be because of change in the traffic, or because of different driving style hence a methodology is to be introduced for different driving pattern to a predetermined routing and this can be done optimisation of the power train, the investigation of the methodology can be done in two methods that are the regular conventional methodology and the proposed methodology the investigation can be carried out in the MATLAB/SIMULINK. The following parameters are considered such as the vehicle body frame, coefficient of rolling resistance, drag coefficient of aerodynamic body, frontal area of vehicle, transmission, and initial battery state of charge (soc) and then the design parameters are considered for the investigation and then based on the result the problem formulation is done and based on that the constraints of the vehicle such as the acceleration, maximum speed, and grade ability for which a supervisory control strategy and then

*Author for correspondence 
for the optimisation a genetic algorithm is used based on the potential solution required, the following procedure is used for the fuel economy evaluation and based on the result the power train components such as the IC-ENGINE, power generator, electric motor, and battery are optimized as required methods for the hybrid electric vehicles. 1

Thereafter, to reduce the pollution caused from the vehicles such as the $\mathrm{CO}_{2}$ emission, various energy sources and various increase in the technologies have to be introduced in the sectors of the vehicle manufacturing industry one amongst such vehicles are the electric vehicle for which a high power electronic semiconductors are used for storing electric energy, the main components include the batteries, inverters, and electric motors hence various efforts are being done for making the components smaller and for improving the efficiency of the components and various efforts to improve the reliability, cooling and vibration resistance in order to resist the harsh automotive environment, to satisfy the requirements a next-generation inverter is used which is developed by the direct water cooling power module by which higher inverter performance and in which compact electric power wiring is used to reduce the inverter size and a better optimum design technique for pin fin heat sinks and having some attachments to minimize the vibration resonance for modifying the structure design to reduce the stresses. The range of air quality index and schematic diagram of the electric vehicle shown in Figures 1 and 2.2, $\underline{3}$

\section{Literature Survey}

Moreover, the energy consumption minimisation strategy (ECMS) for a hybrid electric vehicle introduced, as it imposes SOC sustainability of charge and to increase

\begin{tabular}{|l|}
\hline \multicolumn{2}{|c|}{ Air Quality Index-Particulate Matter } \\
\begin{tabular}{|c|c|}
\hline $301-500$ & Hazardous \\
\hline $201-300$ & Very Unhealthy \\
\hline $151-200$ & Unhealthy \\
\hline $101-150$ & Unhealthy for Sensitive Groups \\
\hline $51-100$ & Moderate \\
\hline $0-50$ & Good \\
\hline
\end{tabular}
\end{tabular}

Figure 1. Air quality index.

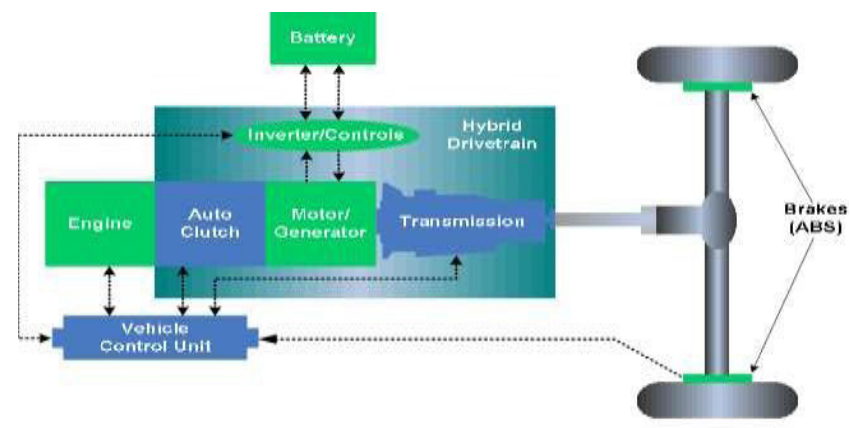

Figure 2. Schematic diagram of a hybrid electric vehicle.

the efficiency of fuel. Initially, factor of equivalent (EF) of the ECM calculated by the pontryagins minimum principle and then a new law is applied plus integral (PI) and fuzzy controller is used in the vehicles to EF of ECMS and at the end the simulations for the dual driving cycles applied ECMS are examine the control strategy called as the rule-base (RB) control based strategy as this adaption results in the improvement and is very robust in ECMS and produces constant EF and has resulted in the better performance for various driving cycles. $\underline{4}$

However, in some of the electric vehicles the source of power for the vehicle can be both from the engine and the batteries, since both the powers are used the architecture of the wheel creates the complexity, hence the proportional power has to be split between them and it has to be judicious, to split the power between them, an AI-based energy management technique has to be employed, as the power is split efficiently it results in improved fuel efficiency and overall performance of hybrid electric vehicles, hence AI-based particle swarm optimisation and genetic algorithm optimisation techniques applied for energy management in hybrid electric vehicles. $\underline{5}$

Thereafter, most of the conventional cars use the hydraulic braking system to slow down the vehicle while in motion, when the brakes are applied to the wheels the brake pads come in contact with the wheels due to which the friction is created from the kinetic energy resulting in energy loss, regenerative braking technology is used in this place where the technology converts the kinetic energy into electrical energy that can be reused for some of the vehicle applications. As the vehicles undergo frequent braking such as in city traffic, however, the system has to be supported from the conventional braking system and a few limitations and these limitations can be overcome by adopting multiple generators with different gear ratios can be used, by which the generators can be used as the 
electric engines and ensure proper speed. And this system can also allow being used in reverse as in the generators can also be used as motors to drive the vehicle. 6

Moreover, the global warming has a leading to heavy environmental impact certain technological developments has been leading in various sector, hence automotive sector has been using electric vehicle as an alternative vehicle for the replacement of conventional vehicles, hence it is necessary to develop a high performance and highly efficient electric vehicle to meet the customer satisfaction in this the combination of electric power cycle with series load. The electric traction power delivered by electric drive train to the converter the analysis and simulation of the vehicle can be carried out in the MATLAB on the various parameters such as the traction power, design of engine/generator, design of gear ratio. Based on the results, the hardware design and the integration of the converter can be done to meet the customer results. $\underline{7}$

However, hybrid electric vehicle needs a different power source to run the vehicle, hence the vehicle need to energy management by controlling the stored energy and production of the energy. This system improves the fuel efficiency comparing with the traditional power trains, to improve the fuel efficiency the system has to adopt highly advanced control strategy required for energy balance between produced and storage required in the system, to maximize power train efficiency, rather than the overall consumption, the system uses a control algorithms that controls the transition among the various operational points, by applying the battery to smooth the engine transmission, as a result of the behavior of the transmission smoothing issues, the implementation of monitor the algorithm by controlled model prediction, and analysis of the UDDS cycle is done based on the two baseline strategies to meet the requirements for the series hybrid vehicle which will show improvement in the fuel economy. $\underline{8}$

Thereafter, the vehicles optimal charging and scheduling and optimal is the mixed fleet in the process of combination of electric vehicles and combustion engines, hence it is required for optimisation of electric vehicles charging in regard to eliminate expensive and highest demands of carbon, hence many operating limitations essentially associated to chargers, electricity grid and electric vehicles grid and to meet the driving range, all this to meet the customer demands and to produce accessible and result oriented tool. Moreover, efficient products which meet the technical and business considerations, which in turn helps in reducing carbon emissions and ownership costs, which will be cost-effective and environmental bearable arrangement in the professional point of view to resolve the problems a combined integer linear design construction applied to avoid electric vehicle scheduling and optimal charging issue and application of CPLEX to resolve the real time problem. ${ }^{9}$

Moreover, the hybrid electric vehicles use power from the batteries as well as the internal combustion engine hence energy management system in these vehicles is very important for the vehicle performance, hence it required to use a suitable energy management system for them to acquire the power for the vehicle hence a fuzzy logic energy management system is used for the charging and discharging batteries issues by three dissimilar profile functions in which the distribution of the power will effects on the results of the power transmission among combined internal combustion engine with the generator and batteries, the shape functions in the simulation produces the triangular membership function of the system as it decides power transmission and minimize the fuel intake, and then using a fuzzy logic control system to optimize the input and output parameters. $\underline{10}$

However, the hybrid electric vehicles use batteries as well as internal combustion engine for the run, in which the batteries work for some range and as they discharge the internal combustion engine completes the rest of the work for the vehicle which results in the decrease of the carbon emissions and increases in the efficiency, in the parallel type hybrid electric vehicles are depends up on the battery and have the capability to recharge outwardly from the power outlet hence an element selection in control approach result in a high degree of hybridisation and the comparative size of the electric motor to the internal combustion engine, hence it describes that high level of increase in the degree of the hybridisation leads to higher overall vehicle efficiency, such as the fuel and energy economy. $\underline{11}$

Thereafter, the energy storage technology in the HEVs has become a trend in the vehicle propulsion hence an alternative energy source for the HEV are proposed in regard with the key parameters of the batter of the hybrid electric vehicle, for different energy sources a typical hybridisation is introduced, namely " $\mathrm{B}+\mathrm{C}$ ", "B+UFLY" as well as the "C+UFLY" where the B denotes the battery and $\mathrm{C}$ denotes the ultra-capacitor and UFLY denotes the ultrahigh-speed flywheel, these transit vehicles under 
high complex road cycles and the configuration involves $\mathrm{Ni}-\mathrm{MH}$ for sole source of energy these results in high energy storage for the better vehicle performance. $\frac{12}{2}$

Moreover, hybrid electric vehicles play an important role in mode of transportation, hence it reduces the emission and maintains the environmental balance, for the proper function of these vehicles a sustainable battery is preferred on which the vehicle efficiency is dependent, usually lithium-ion batteries are used for the electric vehicle, these types of battery having a great scope in the field of electric automobiles, hence a clean, low fuel consuming vehicle is needed for the transportation system, for such vehicles a non-technology based battery is used for the better energy storage of the charge for the application of the hybrid electric vehicles, in this technology the nanostructure materials are used in the battery design, which allows the developed effective in several applications, lithium-ion batteries have many benefits like the great energy concentration, great power delivery, and extensive service life, in great scale applications of the lithium-ion battery toxicity, safety, budget and numerous of raw materials becomes extremely substantial and required discharge criteria can be met by the battery by using nanostructure materials and in parallel with the super capacitors in combination makes the battery to meet the expectation of the customer and is very beneficial in the automobile industry. $\frac{13}{3}$

\section{Results and Discussion}

There have been many state-of-the-art trends in the field of the electric automobile sector. In the recent time frame, to meet the various applications and demands of the transportation industry, nearly of the developments in the vehicle development are the concept cars and series vehicles and then came the HEV and BEV and then the series of which it continued for a decade, and then after some time being the HEV power train architectures and $\mathrm{BEV}$ power train architecture have been taken to produce a large variety of different designs for the power train and then trends started to change in the key technology development such as the battery technology, and then the battery installation place and then the battery capacity and then came the electric machine technology after which the electric machine installation place has to be designed based on the electric power densities along with all these technologies combined to form a modern hybrid electric vehicle with high performance and efficiency to meet the customer demands. $\underline{14}$

Hybrid electric vehicle must be modeled and simulated in the advanced technological, way to meet the customer demands; hence use of hybrid electric vehicle simulator (HEVISM) is preferred, the HEVISM is written in MATLAB/SIMULINK graphical simulation language and is portable to meet the computer specifications, initially comparisons are made on the topologies of the vehicle such as the power assembly, power train, control strategies, and drive cycle after that it is reviewed in the two modes of simulation method such as the forward and backward-facing simulation approaches and the drive train can be designed on the ADVISOR (advanced vehicle simulator) and then based on the simulation of the vehicles parameters such as fuel consumption, vehicle emissions, and complexity can be illustrated for the hybrid electric vehicles. $\frac{15}{}$ The comparison of EVs, HEVs, and FCVs showed in Table 1.

The comparison of EVs, HEVs, and FCVs represents the propulsion, energy storage system, characteristics, source of energy, and major issues between the technologies. Based on comparison, we can examine that which is the most efficient and environmentally friendly.

\section{Conclusions}

We have discussed the HEV merits and demerits, types of vehicle and different management techniques for energy efficiency. Still, we need to explore the different energy sources that will help to reduce pollution in the environment. HEV is a useful product for various industries and consumers. Nowadays, the government of INDIA also supports the HEV and provides the financial and technical supports for the manufacturer and customers and providing the exposure to HEVs and EVs. Definitely, after a few years, it will be a popular product in INDIA due to its better fuel economy and performance. Still, we need to explore the better way of the utilisation of the HEVs for the future perspective and environment-friendly.

\section{Acknowledgement}

The manuscript is prepared by taking assistance from Accendere Knowledge Management Services Pvt. Ltd. We are thankful to them. We also express our gratitude to our teachers and mentor for guiding us throughout the work. 
Table 1. Comparison table of EVs, HEVs, and FCV

\begin{tabular}{|c|c|c|c|}
\hline & EVs & HEVs & FCVs \\
\hline \multirow[t]{2}{*}{ Propulsion } & \multirow[t]{2}{*}{ Electric motor drives } & Electric motor drives & \multirow[t]{2}{*}{ Electric motor drives } \\
\hline & & Internal combustion engine & \\
\hline \multirow{3}{*}{$\begin{array}{l}\text { Energy storage } \\
\text { subsystem }\end{array}$} & Battery & Battery & Hydrogen tank \\
\hline & Supercapacitors & Supercapacitors & $\begin{array}{l}\text { Battery/supercapacitors required to } \\
\text { increase the power density }\end{array}$ \\
\hline & & Fossil or alternative fuels & \\
\hline \multirow[t]{6}{*}{ Characteristics } & Zero local emission & Low local emission & Zero local emission \\
\hline & High energy efficiency & High fuel economy & High energy efficiency \\
\hline & Independent of fossil fuel & Dependent on fossil fuel & Independent of fossil fuel \\
\hline & Short driving range & Long driving range & High cost \\
\hline & The initial cost is high & Higher cost than ICE & Under development \\
\hline & Commercially available & Commercially available & \\
\hline \multirow{2}{*}{$\begin{array}{l}\text { Energy source } \\
\text { infrastructure }\end{array}$} & \multirow[t]{2}{*}{ Electric grid charging facility } & Gasoline station & \multirow[t]{2}{*}{ Hydrogen } \\
\hline & & Electric grid charging & \\
\hline \multirow[t]{4}{*}{ Major issues } & $\begin{array}{l}\text { Battery sizing and } \\
\text { management }\end{array}$ & $\begin{array}{l}\text { Battery sizing and } \\
\text { management }\end{array}$ & Fuel cell cost, life cycle and reliability \\
\hline & Charging facilities & \multirow{3}{*}{$\begin{array}{l}\text { Need to control the energy } \\
\text { sources by management and } \\
\text { optimisation }\end{array}$} & Production of hydrogen \\
\hline & Cost & & \multirow[t]{2}{*}{ Cost } \\
\hline & Battery lifetime & & \\
\hline
\end{tabular}

\section{References}

1. Roy HK, McGordon A, Jennings PA. Real-world investigation of a methodology for powertrain component sizing of hybrid electric vehicles. In: 2013 world electric vehicle symposium and exhibition; 2013. P. 1-9.

2. Nakatsu K, Saito R. The next-generation high power density inverter technology for vehicle. In: 2014 international power electronics conference (IPEC-Hiroshima 2014ECCE ASIA); 2014. P. 1925-8.

3. Graditi G, Langella G, Laterza C, Valenti M. Conventional and electric vehicles: a complete economic and environmental comparison. In: 2015 international conference on clean electrical power; 2015. P. 660-65.

4. Zhang F, Xi J, Langari R. An adaptive equivalent consumption minimization strategy for parallel hybrid electric vehicle based on fuzzy pi. In: 2016 IEEE intelligent vehicles symposium; 2016. P. 460-65.

5. Panday A, Bansal HO. Energy management in hybrid electric vehicles using particle swarm optimization method. In: 2016 IEEE 7th power India international conference; 2016. P. 1-5.
6. Chishty O, Melis WJC. Energy regeneration from decelerating vehicle. In: World congress on sustainable technologies; 2012. P. 12-15.

7. Nayanatara C, Shanmugapriya P, Gurusivakumar G, Thiruvenkadam B. Design \& development of series hybrid electric vehicle. In: 2014 international conference on computation of power, energy, information and communication; 2014. P. 114-17.

8. Di Cairano S, Liang W, Kolmanovsky I V, Kuang ML, Phillips AM. Engine power smoothing energy management strategy for a series hybrid electric vehicle. In: Proceedings of the 2011 American control conference; 2011. P. 2101-06.

9. Salah OB, Oulamara A. Simultaneous electric vehicles scheduling and optimal charging in the business context: case study. In: 5th IET hybrid and electric vehicles conference; 2014.

10. Mahyiddin SH, Mohamed MR, Mustaffa Z, Khor AC, Sulaiman MH, Ahmad H. Fuzzy logic energy management system of series hybrid electric vehicle. In: 4th IET clean energy and technology conference; 2016. 
11. Sreedhar V. Plug-in hybrid electric vehicles with full performance. In: 2006 IEEE conference on electric and hybrid vehicles; 2006. P. 1-2.

12. Wang T, Yu H, Zhu C. Hybrid energy sources for hybrid electric vehicle propulsion. In: 2008 IEEE vehicle power and propulsion conference; 2008. P. 1-4

13. Deshpande VS, Talele MN. Nanotechnology enabled hybrid power system suitable for batteries in hybrid electric vehicle. In: 2017 third international conference on advances in electrical, electronics, information, communication and bio-informatics; 2017. P. 33-35.

14. Frieske B, Kloetzke M, Mauser F. Trends in vehicle concept and key technology development for hybrid and battery electric vehicles. In: 2013 world electric vehicle symposium and exhibition; 2013. P. 1-12.

15. Hou J, Guo X. Modeling and simulation of hybrid electric vehicles using HEVSIM and ADVISOR. In: 2008 IEEE vehicle power and propulsion conference; 2008. P. 1-5. 